GU J Sci, Part C, 5(1): 13-25(2017)

Gazi Üniversitesi
Fen Bilimleri Dergisi
PART C: TASARIM VE TEKNOLOJI
dergipark.gov.tr/http-gujsc-gazi-edu-tr

\title{
Rasemik Propranololün Biyokatalitik Yükseltgenme Tepkimesi için Uygun Mikroorganizma Seçimi
}

\author{
Rahime SONGÜR ${ }^{1, *}$, Ülkü MEHMETOĞLU ${ }^{1}$ \\ ${ }^{I}$ Ankara Üniversitesi, Mühendislik Fakültesi, Kimya Mühendisliği Bölümü, 06100, Tandoğan/ANKARA
}

$\ddot{O} \mathbf{z}$

Makale Bilgisi

Başvuru: 28/12/2016

Düzeltme: $24 / 04 / 2017$

Kabul: $\quad 28 / 07 / 2017$

Anahtar Kelimeler

Propranolol

B-bloker

Yükseltgenme

$A D H$

NADH oksidaz

Keywords

Propranolol

B-blocker

Oxidation

$A D H$

NADH oxidase
Propranolol; farmasötik açıdan önem taşıyan, özellikle kardiyovasküler hastalıkların tedavisinde yaygın olarak kullanılan $\beta$-blokerlardan biridir. $\mathrm{Bu}$ çalışmada, propranololün enantiyomerik saflıkta üretiminin, rasemik propranololün ardışık yükseltgenme-indirgenme tepkimelerini içeren biyokatalitik derasemizasyonu prosesiyle gerçekleştirilmesi amaçlanmaktadır. $\mathrm{Bu}$ kapsamda öncelikle rasemik propranololün yükseltgenme tepkimesinde kullanılacak uygun mikroorganizma araştırılmıștır. Propranololün yükseltgenmesi için alkol dehidrojenaz (ADH) enzimi ve bu enzimin aktivite gösterebilmesi amaciyla ihtiyaç duyulan kofaktörün rejenerasyonu için ise NADH oksidaz enzimi gereklidir. Bu doğrultuda, tepkimede enzim kaynağı olarak kullanılacak mikroorganizmanın seçimi için farklı mikroorganizmalardaki (Lactobacillus kefir NRRL B-1839, Rhodotorula glutunis DSM 70398, Rhizopus oryzae CBS 111718, Rhizopus arrhizus) ADH ve NADH oksidaz aktiviteleri ölçülmüștür. Kullanılan mikroorganizmalar arasında en yüksek ADH ve NADH oksidaz aktivitesi L. kefir'de bulunmuştur.

\section{Selection of Suitable Microorganism for Biocatalytic Oxidation Reaction of Racemic Propranolol}

\begin{abstract}
Propranolol is one of the $\beta$-blockers which are pharmaceutically important, especially used for treatment of cardiovasculer disease. In this study, the production of enantiomerically pure propranolol was aimed via biocatalytic deracemization including tandem oxidation-reduction reactions of racemic propranolol. Within this content, firstly suitable microorganism for the oxidation of racemic propranolol was investigated. Alcohol dehydrogenase (ADH) enzyme for oxidation of propranolol and NADH oxidase enzyme for cofactor regeneration were necessary for the oxidation reactions. For this reason, ADH and NADH oxidase enzymes activities of different microorganisms were measured to select the microorganism for using as enzyme source. These microorganisms are Lactobacillus kefir NRRL B-1839, Rhodotorula glutunis DSM 70398, Rhizopus oryzae CBS 111718, Rhizopus arrhizus. The highest ADH and NADH oxidase activities were obtained for $L$. kefir.
\end{abstract}

\section{GİRIŞ (INTRODUCTION)}

İlaç endüstrisi için önemli kiral bileşikler kimyasal yöntemlerle sentezlendiğinde genellikle rasemik karışım şeklindedir. Genel olarak kiral bileşiklerin sadece bir enantiyomeri istenen biyolojik aktiviteye sahiptir. Diğer enantiyomer ise bir biyolojik aktivite göstermez ve safsızlık olarak nitelendirilir, yan ve toksik etki gösterebilir ya da diğer enantiyomerin etkisini azaltacak yönde çalışabilir. Bu yüzden tek enantiyomer formunda kiral ürünlerin üretimi ilaç endüstrisinde önem kazanmaktadır.

İlaç tedavisinde tek enantiyomerin kullanılması gerekliliği, otoriteleri ilaçlar üzerindeki düzenlemeleri sıkılaştırmaya yöneltmiştir. Bu durum ilaç teknolojisinde yeni gelişmeler sağlamış olup tek-enantiyomer elde etmek amaciyla pek çok çalışma başlatılmıştır [1]. Fakat, enantiyomerik saflıktaki ilaçlara olan istek her ne kadar artsa da hala birçok ilaç rasemat olarak satılmaktadır [2]. 
Toplumda kardiyovasküler hastalıklara çok sık rastlanılır [3] ve $\beta$-blokerlar bu hastalıkların tedavisinde yaygın olarak kullanılan çok önemli bir ilaç grubudur [4]. $\beta$-blokerların enantiyomerleri çoğunlukla farklı farmakokinetik ve farmakodinamik özelliklere sahiptir. Bu nedenle $\beta$-bloker enantiyomerleri ayrı ayrı kullanılmalıdır [1]. $\beta$-adrenerjik bloker aktivitesine sahip bileşiklerden en önemlileri propranolol, atenolol, metoprolol ve alprenololdür [5]. Propranolol hipertansiyon, migren ağrısı, prekardiyal rahatsızlığa bağlı gögüs ağrısı, kalp ritim bozuklukları, yüksek tansiyona sebep olan bir böbreküstü bezi vasküler tümörü tedavisi için kliniklerde kullanılmaktadır [6,7]. Bir sekonder amino-alkol olan propranolol ticari olarak rasemik karışım halinde satılmaktadır. Fakat rasemik halde astım hastalarında bronşların daralması ve hipertansiyon hastalarında diyabete neden olan yan etkilere sahiptir. Bu etkiler Renantiyomerinden kaynaklanmaktadır [8]. Fakat, R-propranolol de hipertiroid tedavisinde [9] ve ayrica doğum kontrol haplarında [10] kullanılmaktadır. Bu nedenle enantiyomerik saflıkta $\mathrm{R}$ ve S-propranololün elde edilmesi için farklı yöntemler denenmektedir.

Enantiyomerik saflıkta bileşenlerin elde edilmesinde, mikrobiyal stereoinversiyon ile derasemizasyon yöntemi en ilgi çekici yöntemlerden biridir [11]. Enzim saflaştırma pahalı ve zahmetli olduğundan izole enzimler çok pahalıdır. Biyokatalizör olarak izole enzimler yerine mikrobiyal tüm hücre kullanılması prosesin ekonomikliği açısından oldukça avantajlıdır. Özellikle yükseltgenme-indirgenme biyotransformasyonlarında kofaktörler gereklidir [12] ve kofaktörler (NAD $(H), N A D P(H)$ gibi) pahalıdır [11]. Bu nedenle, enzim kaynağı olarak mikrobiyal tüm hücre kullanıldığında hücre içinde bulunan ve rejenere olan kofaktörler prosesin ekonomikliğini sağlaması açısından oldukça önemlidir [12,13].

$\mathrm{Bu}$ çalışmada incelenen önemli bir $\beta$-bloker olan rasemik propranololün biyotransformasyonu konusunda literatürde sadece tek bir çalışma bulunmaktadır [14]. Buna rağmen, çalışmada tepkimenin gerçekleşme mekanizmasına ve tepkimeyi katalizleyen enzimlere dair hiçbir bilgi bulunmamaktadır. Bu çalışmada ise, propranololün enantiyomerik saflıkta üretiminin, rasemik propranololün ardışı yükseltgenmeindirgenme tepkimelerini içeren biyokatalitik derasemizasyonu prosesiyle gerçekleştirilmesi amaçlanmaktadır. $\mathrm{Bu}$ kapsamda öncelikle rasemik propranololün yükseltgenme tepkimesinde kullanılacak uygun mikroorganizma araştırılmıştır. Bu tepkimeyi katalizleyecek alkol dehidrojenaz $(\mathrm{ADH})$ enzimi hücre içi bir enzimdir. $\mathrm{NAD}^{+}$'nın NADH'ye indirgenmesi ile alkollerin aldehit ya da ketonlara dönüşümünü sağlamaktadır [15]. Yükseltgenme tepkimesinin gerçekleşebilmesi için NAD $^{+}$nın rejenerasyonu önem taşımaktadır ve biyokatalitik olarak gerçekleştirilmesi daha kolaydır. Örneğin, NADH oksidaz enzimi moleküler oksijenden hidrojen peroksit ya da su oluşumunu katalizlerken aynı zamanda NADH'nin $\mathrm{NAD}^{+}$ya yükseltgenmesini de gerçekleştirerek kofaktör rejenerasyonunu sağlamaktadır. Kofaktör rejenerasyonu için kosubstrat gerektirmemesi ve böylece yan ürün oluşturmaması açısından NADH oksidaz enziminin kullanılması avantajlıdır [13]. Bu nedenle, çalışmada propranololün yükseltgenmesi için ADH enzimi ve kofaktör rejenerasyonu için NADH oksidaz enzimi gereklidir. Prosesin ekonomikliğini sağlamak açısından bu iki enzimi ve kofaktörlerini içeren mikroorganizmalar araştırılmıştır.

\section{DENEYSEL YÖNTEM (EXPERIMENTAL METHOD)}

\subsection{Kullanılan Mikroorganizmaların Üreme Koşulları (Growth Conditions of Using Microorganisms)}

\subsubsection{Lactobacillus kefir Mikroorganizmasının Üreme Koşulları (Growth Conditions of Lactobacillus kefir)}

Lactobacillus kefir NRRL B-1839 'Agricultural Research Service Culture Collection (NRRL)'den temin edilmiştir. L. kefir bileşimi $22 \mathrm{~g} / \mathrm{L}$ glikoz, $10 \mathrm{~g} / \mathrm{L}$ kazein pepton, $5 \mathrm{~g} / \mathrm{L}$ sodyum asetat, $5 \mathrm{~g} / \mathrm{L}$ maya özütü, $10 \mathrm{~g} / \mathrm{L}$ et özütü, $2 \mathrm{~g} / \mathrm{L} \mathrm{K}_{2} \mathrm{HPO}_{4}, 1 \mathrm{~g} / \mathrm{L}$ Tween $80,0.2 \mathrm{~g} / \mathrm{L} \mathrm{MgSO}_{4} .7 \mathrm{H}_{2} \mathrm{O}, 0.05 \mathrm{~g} / \mathrm{L} \mathrm{MnSO}_{4} \cdot \mathrm{H}_{2} \mathrm{O}$ 'dan oluşan $100 \mathrm{~mL}$ üreme ortamında, $35^{\circ} \mathrm{C}, 150 \mathrm{rpm}$ koşullarında 1 gün süresince çoğaltılmıştır.

\subsubsection{Rhizopus oryzae Mikroorganizmasının Üreme Koşulları (Growth Conditions of Rhizopus oryzae)}

Rhizopus oryzae CBS 111718 küfü 'Centraalbureau voor Schimmelcultures Culture Collection'dan satın alınmıştır. $R$. oryzae ilk olarak bileşimi $20 \mathrm{~g} / \mathrm{L}$ glikoz, $20 \mathrm{~g} / \mathrm{L}$ malt özütü, $20 \mathrm{~g} / \mathrm{L}$ agar ve $1 \mathrm{~g} / \mathrm{L}$ peptondan 
oluşan, pH'1 6,6 olan katı üreme ortamında $30^{\circ} \mathrm{C}^{\prime} \mathrm{de}$, 4-9 gün süresince çoğaltılmıştır. Katı üreme ortamında çoğaltılan sporlar steril suya aktarılarak spor çözeltisi hazırlanmıştır. Thoma lamı ile mikroskopta spor sayımı yapılmış ve başlangıç spor sayısı $5 \times 10^{5}$ olacak şekilde sıvı üreme ortamına ekim yapılmıştır. $20 \mathrm{~g} / \mathrm{L}$ glikoz, $5 \mathrm{~g} / \mathrm{L}$ maya özütü, $5 \mathrm{~g} / \mathrm{L}$ sodyum klorür ve $10 \mathrm{~g} / \mathrm{L}$ triptondan oluşan ve pH'1 5 olan $100 \mathrm{~mL}$ sıvı üreme ortamında mikroorganizma üretimi $30^{\circ} \mathrm{C}$ 'de, $150 \mathrm{rpm}$ karıştırma hızında 2 günde gerçekleştirilmiştir.

\subsubsection{Rhizopus arrhizus Mikroorganizmasının Üreme Koşulları (Growth Conditions of Rhizopus arrhizus)}

Rhizopus arrhizus küfü Ankara Üniversitesi Biyoloji Bölümü’nden temin edilmiştir. $R$. arrhizus, PDA (patates dekstroz agar) katı üreme ortamında, $30^{\circ} \mathrm{C}$ 'de, 4 gün süresince çoğaltılmıştır. Spor çözeltisi $R$. oryzae mikroorganizmasıyla aynı yöntemle hazırlanmış, mikroskopta sayımı yapılmış ve sııı üreme ortamına aktarılmıştır. Sıvı üreme ortamı, $20 \mathrm{~g} / \mathrm{L}$ glikoz ve $4 \mathrm{~g} / \mathrm{L}$ patates ekstraktından oluşan ve pH'1 5,1 olan PDB (patates dekstroz besiyeri) ortamıdır. $100 \mathrm{~mL}$ hacmindeki bu ortamda hücre üretimi; $30^{\circ} \mathrm{C}$ 'de, 150 rpm karıştırma hızındaki orbital çalkalayıcıda, 2 günde gerçekleştirilmiştir.

\subsubsection{Rhodotorula glutunis Mikroorganizmasının Üreme Koşulları (Growth Conditions of Rhodotorula glutunis)}

Rhodotorula glutunis DSM 70398 Leibniz Institute DSMZ (German Collection of Microorganisms and Cell Cultures)'den satın alınmıştır. R. glutunis bileşimi $10 \mathrm{~g} / \mathrm{L}$ glikoz, $5 \mathrm{~g} / \mathrm{L}$ pepton, $3 \mathrm{~g} / \mathrm{L}$ maya özütü, 3 $\mathrm{g} / \mathrm{L}$ malt özütünden oluşan $100 \mathrm{~mL}$ UYM ortamında (genel maya üreme ortamı), $30^{\circ} \mathrm{C}, 150 \mathrm{rpm}$ 'de 2 gün süreyle çoğaltılmıştır.

\subsection{Ses Ötesi Dalga (SÖD) Uygulama Yöntemi (The Method of Ultrasonication Application)}

Mikroorganizmaların ADH ve NADH oksidaz enzim aktivitelerine bakmak amacıyla sırasıyla hücre içinde ve hücre zarında olduğu bilinen bu enzimlerin serbest kalması için mikroorganizmalara SÖD uygulanmıştır. SÖD uygulama koşulları literatür araştırması ile belirlenmiştir. Hücrelerin parçalanarak içindeki enzim/proteinlerin salımı için mikrobiyolojide standart bir yöntem olarak akustik kavitasyon üreten, genellikle 20 ya da $40 \mathrm{kHz}$ frekansta, SÖD kullanılmaktadır [16]. 15-20 kHz'den yüksek frekanstaki ses dalgaları enzimde aktivite kaybına neden olabileceğinden [17] bu çalışmada hücrelere 20 $\mathrm{kHz}$ frekansta SÖD uygulanmıştır. SÖD uygulanırken ortamdaki hücre derişimi $\% 20(\mathrm{w} / \mathrm{v})$ 'den fazla olmamalıdır. Yüksek derişim hücre parçalanmasında verimliliğin düşmesine neden olur. SÖD ile hücre homojenizasyonunda genelde $\% 5$ 'lik hücre süspansiyonu kullanılır [18]. Hücre derişimi ağırlıkça \%5'in üzerine çıktığında enerji avantaj miktarı da azalır [19]. Bu nedenle, bu çalışmada \%4 (w/v) oranında hücre süspansiyonu kullanılmıştır. ADH enzimi de dahil olmak üzere farklı enzimlere SÖD uygulama parametrelerinin incelendiği Özbek ve Ülgen (2000) çalışmasında [20] enzimlere uygulanan akustik güç arttıkça enzimin aktivitesi azalmıştır. Aynı zamanda uygulama sonrasında enzimin kararlılığı incelendiğinde uygulanan akustik güç arttıkça enzimin zamanla aktivite kaybının da arttığı tespit edilmiştir. Bu nedenle, bu çalışmada kullanılan SÖD cihazı ile hücrelere uygulanabilecek en düşük güç değerleri (40 ve $80 \mathrm{~W}$ ) uygulanmıştır. SÖD ile parçalamada yüksek akustik güç nedeniyle serbest radikal oluşumu gerçekleşir. Bu durum ise hücrelerden kararsız moleküllerin salımına neden olarak zararlı olabilir. Serbest radikal üretimini azaltmak için "duty cyle control” kullanılarak SÖD enerjisi çözeltiye kesikli olarak verilebilir [20]. Bu nedenle bu çalışmada SÖD, kesikli olarak uygulanmıştır. Özbek ve Ülgen (2000) çalışmasında [20] SÖD uygulama süresi arttıkça ADH enzim aktivitesinin düştüğü sonucuna varıldığından bu çalışmada SÖD hücrelere kısa sürelerde (2-3 dk) uygulanmıştır. Tüm bu çalışmalar incelenerek, bu çalışmada hücreler $6000 \mathrm{rpm}, 4^{\circ} \mathrm{C}, 20 \mathrm{dk}$ santrifüjlendikten sonra üreme ortamı ile $\% 4(\mathrm{w} / \mathrm{v})$ oranında hücre süspansiyonu hazırlanmıştır. $20 \mathrm{kHz}$ frekansta $\mathrm{SÖD}, 40$ ve $80 \mathrm{~W}$ güçte, kesikli olarak (1s uygulama+1s ara), kısa sürelerde (2-3 dk) uygulanmıştır (Bandelin Sonopuls HD3400 Ultrasonic homogenizer, $400 \mathrm{~W} ; 1,9 \mathrm{~cm}$ çaplı prop). Aynı zamanda, ultrasonik prop $20 \mathrm{ml}$ hacimdeki hücre süspansiyonuna $2 \mathrm{~cm}$ derinliğinde daldırılarak SÖD uygulanmıştır [21]. Parçalamadan sonra bekleme süresi arttıkça enzimin aktivitesi düştügünden [20], uygulama sonrasında hücreler bekletilmeden aktivite ölçümleri yapılmıştır. SÖD uygulanırken hücre süspansiyonunun bulunduğu beher, uygulama sırasında artan sıcaklığın enzim aktivasyonunu düşürmemesi için buz banyosuna oturtulmuştur [21]. 


\subsection{ADH Aktivitesi Belirleme Yöntemi (The Method of ADH Activity Determination)}

SÖD uygulandıktan sonra hücre süspansiyonu, $20 \mathrm{mM}$ etanol çözeltisi ve $20 \mathrm{mM} \beta$-NAD (pH 7 fosfat tamponundaki çözeltisi) içeren karışıma eklenmiş ve UV Spektrofotometresinde $340 \mathrm{~nm}$ dalga boyunda analizlenmiştir. Burada $\mathrm{ADH}$ enzimlerinin katalizlediği etil alkolün yükseltgenme tepkimesiyle oluşan $\beta$ NADH'ın $340 \mathrm{~nm}$ dalga boyunda absorbansta neden olduğu artış ölçülmektedir [22]. Tepkime spektrofotometre küveti içinde takip edilmiştir.

$$
\text { Etanol }+\beta-\mathrm{NAD} \quad \stackrel{\mathrm{ADH}}{\rightarrow} \text { Asetaldehit }+\beta-\mathrm{NADH}
$$

UV spektrofotometrede $340 \mathrm{~nm}$ 'de takip edilen absorbansın zamanla değişiminin eğiminden birim zamandaki absorbans değişimi bulunmuştur. Şekil 1'deki $\beta$-NADH'a ait kalibrasyon grafiğinden birim zamanda birim hacimde oluşan NADH mol sayısı ve dolayısıyla harcanan etanol mol sayısı hesaplanmıştır. 1 ünite $(\mathrm{U}) ; 25^{\circ} \mathrm{C}, \mathrm{pH}$ 7'de herbir dakikada $1 \mu \mathrm{mol}$ etanolü asetaldehite dönüştüren enzim miktarıdır [22].

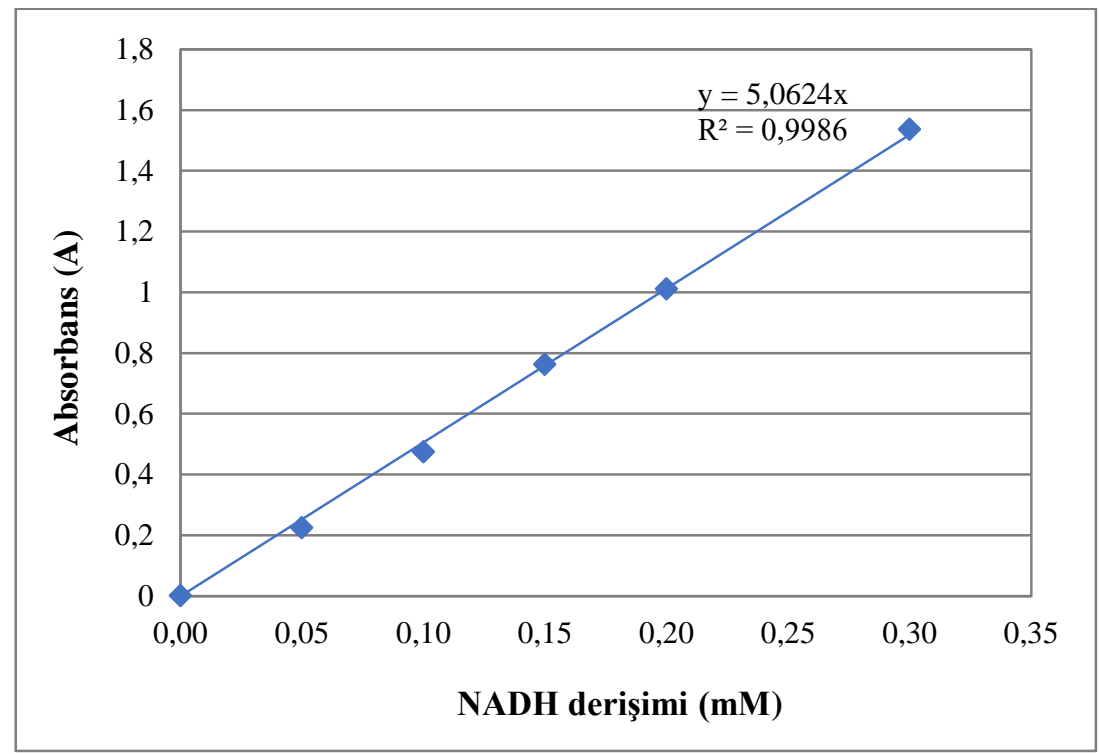

Şekil 1. $\beta$-NADH kalibrasyon grafiği (The calibration graph of $\beta$-NADH)

\subsection{NADH Oksidaz Aktivitesi Belirleme Yöntemi (The Method of NADH Oxidase Activity Determination)}

Hücre süspansiyonu SÖD uygulandıktan sonra $1 \mathrm{mM}$ dithiotreitol ve $0,1 \mathrm{mM} \beta-\mathrm{NADH}(\mathrm{pH}$ 7,5 potasyum fosfat tamponundaki çözeltisi) içeren karışıma eklenmiş ve UV Spektrofotometresinde $340 \mathrm{~nm}$ dalga boyunda analizlenmiştir [23]. Burada NADH oksidaz enzimlerinin katalizlediği $\mathrm{O}_{2}$ 'nin $\mathrm{H}_{2} \mathrm{O}_{2}$ 'ye dönüşümü tepkimesiyle azalan $\beta$-NADH'ın $340 \mathrm{~nm}$ dalga boyunda absorbansta neden olduğu azalış ölçülmektedir. 1 ünite $(\mathrm{U}) ; 25^{\circ} \mathrm{C}, \mathrm{pH} 7,5^{\prime}$ da herbir dakikada $1 \mu$ mol $\beta$-NADH'1 dönüştüren enzim miktarıdır. Enzim aktiviteleri, Şekil 1'deki kalibrasyon grafiği kullanılarak ADH enzim aktivitesinin hesaplanma yöntemiyle benzer şekilde hesaplanmıştır.

$$
\mathrm{O}_{2}+\beta-\mathrm{NADH}+\mathrm{H}^{+} \rightarrow \quad \mathrm{H}_{2} \mathrm{O}_{2}+\beta-\mathrm{NAD}^{+}
$$




\subsection{L. kefir Mikroorganizmast ile Biyotransformasyon Tepkimesi (Biotransformation Reaction Using L. kefir)}

Biyokatalitik derasemizasyon tepkimesinde substrat olarak kullanılan rasemik propranolol Sigma'dan temin edilmiş ve tepkimede kullanılmak üzere Tris- $\mathrm{HCl}(50 \mathrm{mM}, \mathrm{pH} 7,5)$ tamponunda çözünmüştür. Üreyen hücreler $4500 \mathrm{rpm}, 4^{\circ} \mathrm{C}, 10 \mathrm{dk}$ santrifüjlendikten sonra tepkime ortamında başlangıç hücre derişimi 20-400 g/L olacak şekilde, hassas terazide tartılıp $(0,2-4 \mathrm{~g}) 10 \mathrm{~mL}$ tampon ortamı içeren tepkime kabına eklenmiş ve $30^{\circ} \mathrm{C}, 180 \mathrm{rpm}$ 'de tepkimeler gerçekleştirilmiştir. Kofaktör rejenerasyonunu sağlayacak olan tepkimenin substratı moleküler $\mathrm{O}_{2}$ olduğundan $250 \mathrm{~mL}$ 'lik tepkime kabı kullanılmıştır. Tepkime süresi sonunda tepkime ortamı kloroformla ekstrakte edilmiş, çözücüsü uzaklaştırılmış ve etanolde çözülerek HPLC analizine hazırlanmıştır.

\subsection{Propranololün HPLC Analizi (HPLC Analysis of Propranolol)}

Tepkime sonunda analizler HPLC'de (Thermo Finnigan Spectra System) Chiralcel OD (4,6 x 250 mm, 10 $\mu \mathrm{m})$ kolonu kullanılarak yapılmıştır. Hareketli faz olarak hekzan ve etanol kullanılmış; $0,8 \mathrm{~mL} / \mathrm{min}$ akış hızı, UV dedektör $280 \mathrm{~nm}$ dalga boyu, $20 \mu \mathrm{L}$ enjeksiyon hacmi koşullarında analizler gerçekleştirilmiştir.

Analiz sonuçlarına göre \% ee ve \% C hesabı yapılmıştır. \% ee propranololün enantiyomerik aşırılığını ifade etmekte ve Eşitlik (1)'den hesaplanmaktadır. \% C ise (S)-propranololün dönüşümünü ifade etmekte ve Eşitlik (2)'den hesaplanmaktadır.

$$
\% e e=\frac{C_{R}-C_{S}}{C_{R}+C_{S}} x 100
$$

Burada; $C_{R}$ ve $C_{S}$ sirasıyla (R)-propranolol ve (S)-propranololün derişimini ifade etmektedir.

$$
\% C=\frac{C_{S o}-C_{S}}{C_{S o}} \times 100
$$

Burada; $\mathrm{C}_{\mathrm{So}}$ ve $\mathrm{C}_{\mathrm{S}}$ sırasıyla (S)-propranololün başlangıç derişimini ve tepkime sonrasında ortamda kalan (S)-propranololün derişimini ifade etmektedir.

\section{BULGULAR VE TARTIŞMA (RESULTS AND DISCUSSION)}

Kardiyovasküler hastalıkların tedavisinde yaygın olarak kullanılan $\beta$-blokerlardan biri olan propranololün enantiyomerik saflıkta üretimi önem taşımaktadır. Bu çalışmada, rasemik propranololün çoklu enzim sistemi ile ardışı yükseltgenme-indirgenme tepkimeleri gerçekleştirilerek enantiyomerik saflıkta propranolol üretimi amaçlanmaktadır (Şekil 2). Bunun için çalışmanın bu kısmında Şekil 2'deki mekanizmanın ilk basamağı olan yükseltgenme tepkimesi ele alınmış ve bu tepkimeyi katalizleyecek uygun mikroorganizma belirlenmeye çalışılmıştır.

Şekil 2'deki derasemizasyon mekanizmas1, biyokatalitik derasemizasyon ile enantiyomerik saflıkta sekonder alkol üretimi konusundaki çalışmalar [24] referans alınarak önerilmiştir. Burada yükseltgenme tepkimesi ADH enzimi katalizörlügüünde gerçekleşecektir. Fakat, ADH kofaktör gerektiren bir enzimdir ve kofaktörler pahalıdır [25]. Bu nedenle tüm hücre kullanıldığı durumda hücre içinde bulunan ve rejenere olan kofaktörler prosesin ekonomikliğini sağlaması açısından oldukça önemlidir. Örneğin, NADH oksidaz enziminin moleküler oksijenden su ya da hidrojen peroksit $\left(\mathrm{H}_{2} \mathrm{O}_{2}\right)$ oluşumunu katalizlerken aynı zamanda kofaktör rejenerasyonunu sağladığı bilinmektedir. Kofaktör rejenerasyonu için kosubstrat gerektirmemesi ve böylece yan ürün oluşturmaması açısından NADH oksidaz enziminin 
kullanılması avantajlıdır [13]. Tüm bu nedenlerle yükseltgenme tepkimesinde kullanılmak üzere ADH ve NADH oksidaz enzimlerini içeren bir mikroorganizma araştırılmıştır.<smiles>CC(C)NCC(O)COc1cccc2ccccc12</smiles>

(R)-propranolol<smiles>CC(C)NC[C@H](O)COc1cccc2ccccc12</smiles>

(S)-propranolol

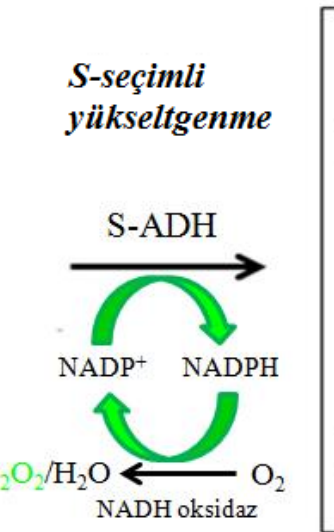

NADH oksidaz<smiles>CC(C)NCC(O)COc1cccc2ccccc12</smiles>

(R)-propranolol<smiles>CCNCC(=O)COc1cccc2ccccc12</smiles>

R-seçimli indirgenme

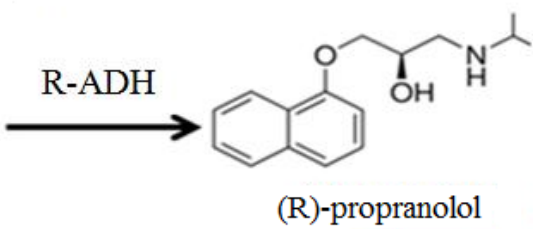

Şekil 2. Ardlşık yükseltgenme-indirgenme tepkimeleri ile rasemik propranololün biyokatalitik derasemizasyonu (Biocatalytic deracemization of racemic propranolol via tandem oxidation and reduction reactions)

\subsection{Lactobacillus kefir'de Bulunan NADH Oksidaz Enzim Aktivitesinin Belirlenmesi (Determination of NADH Oxidase Activity in L. kefir)}

Lactobacillus kefir mikroorganizmasının ADH enzimini içerdiği bilinmektedir [26]. NADH oksidaz enzimini içerip içermediği ise enzim aktivitesi ölçülerek araştırılmıştır. Geueke vd. (2003) çalışmasından Lactobacillus brevis mikroorganizmasının $\mathrm{O}_{2}$ 'li ortamda üretildiğinde $\mathrm{NADH}$ oksidaz aktivitesinin, $\mathrm{O}_{2}$ 'siz ortamda üretildiğinde $\mathrm{ADH}$ aktivitesinin daha yüksek olduğu bilgisi edinilmiştir [27]. Bu nedenle L. kefir $\mathrm{O}_{2}$ 'li ve $\mathrm{O}_{2}$ 'siz ortamda üretilerek enzim aktivitesi ölçülmüştür. Her iki ortamda üretilen $L$. kefir'e SÖD uygulanmadan ve SÖD uygulanarak $(20 \mathrm{kHz}, 80 \mathrm{~W}, 1 \mathrm{dk}$ sürekli SÖD+1 dk ara, $3 \mathrm{kez}$ uygulama, hücre üreme ortamında) hücre süspansiyonları hazırlanmıştır. Bu süspansiyonların NADH oksidaz aktivitelerine bakılmıș ve absorbansın zamanla değișimi Şekil 3'te, aktivitelerin sayısal değerleri Tablo 1'de verilmiştir. Buna göre, $\mathrm{O}_{2}$ 'li ve $\mathrm{O}_{2}$ 'siz ortamda üretilen mikroorganizmaların NADH oksidaz aktivitelerinin çok yakın olduğu, fakat SÖD uygulanmasının hücre zarında bulunan NADH oksidazın serbest kalması için çok etkili olduğu gözlenmiştir. SÖD uygulanmış hücre süspansiyonlarında enzim aktivitesi yaklaşık 100 kat daha fazla bulunmuştur. 


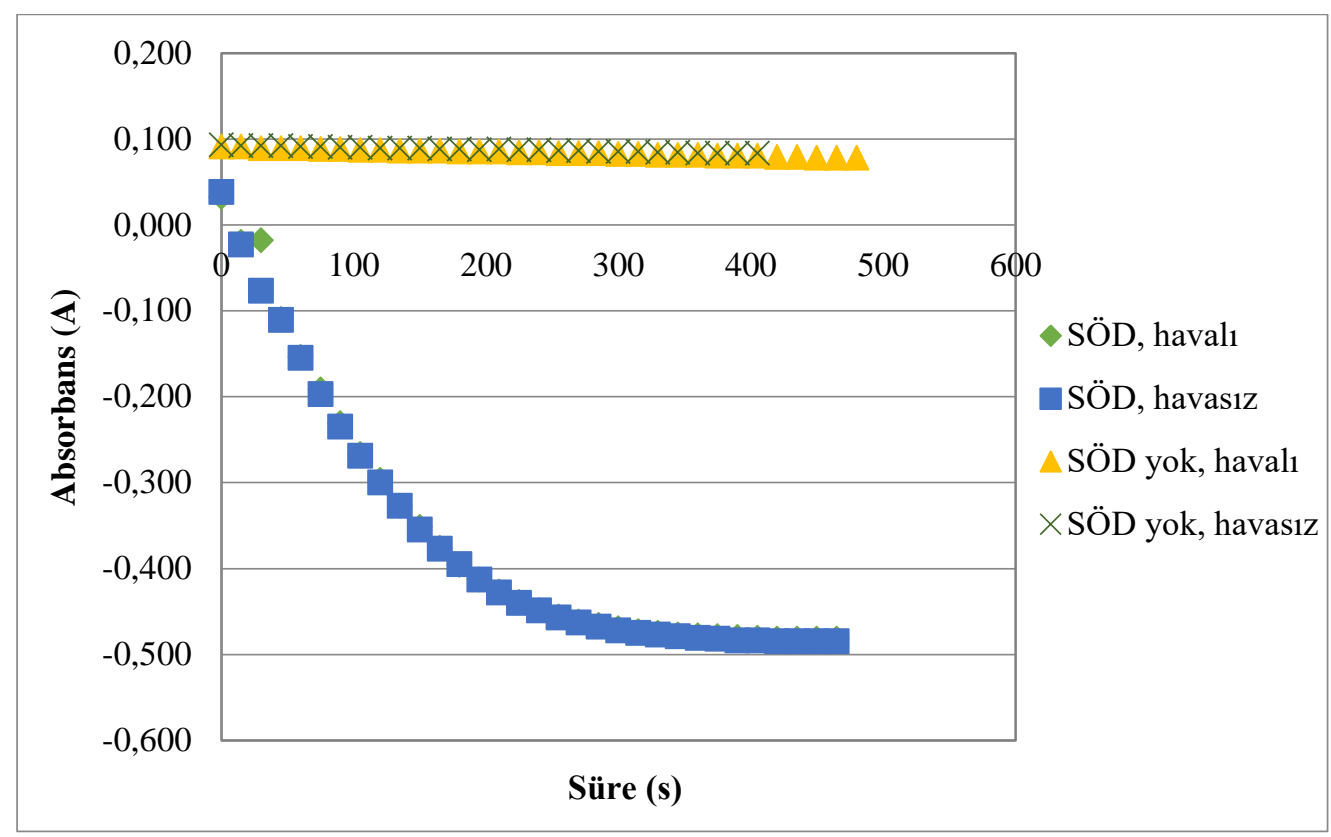

Şekil 3. L. kefir'de NADH oksidaz aktivitesi ölçümü sırasında absorbansin zamanla değişimi $(\lambda=340 \mathrm{~nm}$, $1 \mathrm{mM}$ dithiotreitol, 0,1 mM NADH (pH 7,5 potasyum fosfat tamponu), SÖD (20 kHz, $80 \mathrm{~W}$, (1 dk sürekli $S O ̈ D+1$ dk ara) $x 3 \mathrm{kez})$ ) (The changing absorbans value with time during determinating NADH oxidase activity in L. kefir)

Tablo 1. L. kefir'deki NADH oksidaz aktiviteleri ( $\lambda=340 \mathrm{~nm}, 1 \mathrm{mM}$ dithiotreitol, $0,1 \mathrm{mM} N A D H(p H$ 7,5 potasyum fosfat tamponu), SÖD (20 kHz, $80 \mathrm{~W}$, (1 dk sürekli SÖD+1 dk ara) $x 3 \mathrm{kez}))(\mathrm{NADH}$ oxidase activity in L. kefir)

\begin{tabular}{lc}
\hline Hücre & Aktivite $(\mathbf{U} / \mathbf{m L})$ \\
\hline SÖD uygulanmış, $\mathrm{O}_{2}{ }^{\prime}$ li ortamda üretilen & 0,531 \\
SÖD uygulanmış, $\mathrm{O}_{2}$ 'siz ortamda üretilen & 0,572 \\
SÖD uygulanmamış, $\mathrm{O}_{2}{ }^{\prime}$ li ortamda üretilen & 0,0046 \\
SÖD uygulanmamış, $\mathrm{O}_{2}$ 'siz ortamda üretilen & 0,0045 \\
\hline
\end{tabular}

\subsection{Farklı Mikroorganizmalarn ADH ve NADH Oksidaz Aktivitelerinin Belirlenmesi (Determination of ADH and NADH Oxidase Activities in Different Microorganisms)}

Farklı mikroorganizmaların ADH ve NADH oksidaz enzim aktiviteleri belirlenerek yükseltgenme tepkimesini katalizleyecek L. kefir'den daha yüksek enzim aktivitesine sahip mikroorganizma araştırılmıştır. Bu amaçla Rhodotorula glutunis DSM 70398, Rhizopus oryzae CBS 111718, Rhizopus arrhizus ve karşılaştırma amacıyla Lactobacillus kefir NRRL B-1839 mikroorganizmalarına SÖD (40 W güçteki $20 \mathrm{kHz}$ SÖD, 1s uygulama $+1 \mathrm{~s}$ ara olacak şekilde $2 \mathrm{dk}$ ) uygulanmıştır. SÖD uygulanarak hazırlanan hücre süspansiyonlarının $\mathrm{ADH}$ ve NADH oksidaz aktiviteleri ölçülmüştür. Buna göre; zamanla elde edilen absorbans değişimleri Şekil 4 ve Şekil 5'te, hesaplanan aktivite değerleri Tablo 2 ve Tablo 3'te verilmiştir. Rhizopus oryzae ve Rhizopus arrhizus'da NADH oksidaz aktivitesine rastlanmamıştır. Buna göre, kullanılan mikroorganizmalar arasında ADH ve NADH oksidaz aktivitesi en yüksek olan mikroorganizma L. kefir olarak belirlenmiştir. 


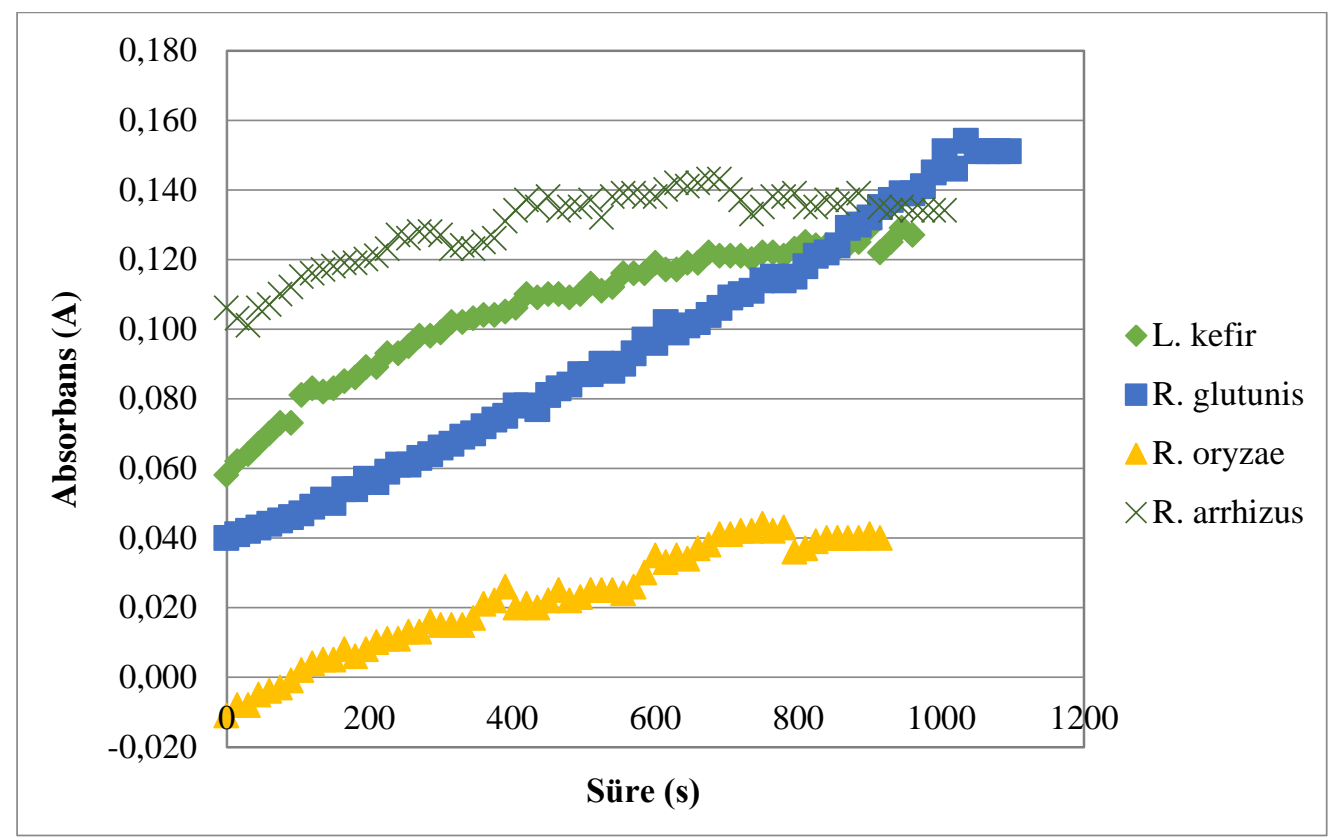

Şekil 4. Farklı mikroorganizmalarda ADH aktivitesi ölçümü sirasında absorbansın zamanla değişimleri ( $\lambda=340 \mathrm{~nm}, 20 \mathrm{mM}$ etanol ve $20 \mathrm{mM} \beta$-NAD (pH 7 fosfat tamponundaki çözeltisi), SÖD (40 W, $20 \mathrm{kHz}$ $S O ̈ D, 1 s$ uygulama $+1 s$ ara olacak şekilde $2 d k)$ ) (The changing absorbans value with time during determinating ADH activities in different microorganisms)

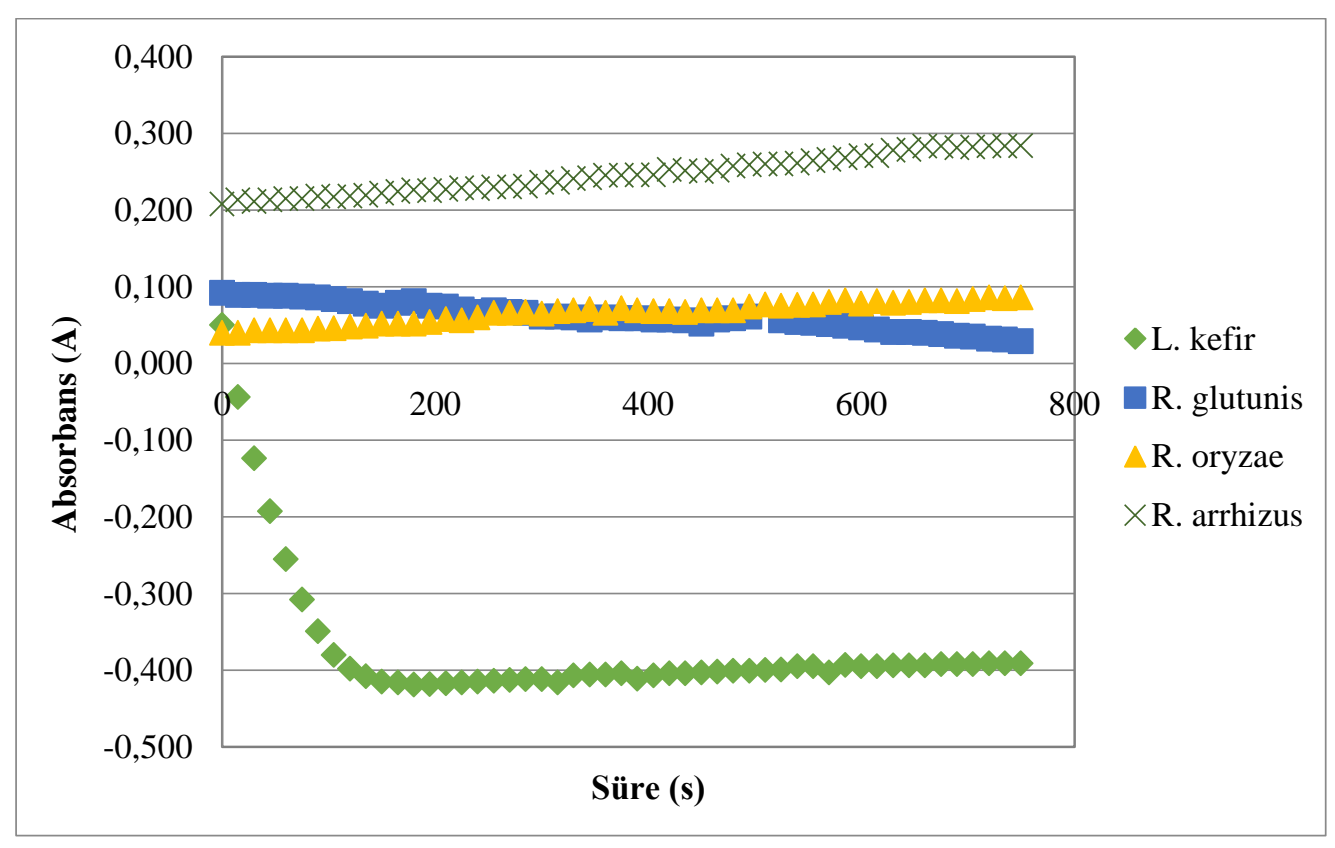

Şekil 5. Farklı mikroorganizmalarda NADH oksidaz aktivitesi ölçümü sirasında absorbansın zamanla değişimleri $(\lambda=340 \mathrm{~nm}, 1 \mathrm{mM}$ dithiotreitol, $0,1 \mathrm{mM} \mathrm{NADH}$ ( $\mathrm{pH}$ 7,5 potasyum fosfat tamponu), SÖD (40 W, $20 \mathrm{kHz} S O ̈ D, 1 s$ uygulama +1 s ara olacak şekilde $2 \mathrm{dk}$ )) (The changing absorbans value with time during determinating NADH oxidase activities in different microorganisms) 
Tablo 2. ADH aktiviteleri ( $\lambda=340 \mathrm{~nm}, 20 \mathrm{mM}$ etanol, $20 \mathrm{mM} \beta$-NAD (pH 7 fosfat tamponundaki çözeltisi), $S O ̈ D(40 \mathrm{~W}, 20 \mathrm{kHz} S O ̈ D, 1 s$ uygulama +1 s ara olacak şekilde $2 \mathrm{dk}))$ (ADH activities)

\begin{tabular}{lc}
\hline Mikroorganizma & Aktivite (U/mL) \\
\hline L. kefir $\left(\mathrm{O}_{2}\right.$ 'siz ortamda üretilen) & 0,0370 \\
R. glutunis & 0,0161 \\
R. oryzae & 0,0205 \\
R. arrhizus & 0,0156 \\
\hline
\end{tabular}

Tablo 3. $N A D H$ oksidaz aktiviteleri $(\lambda=340 \mathrm{~nm}, 1 \mathrm{mM}$ dithiotreitol, $0,1 \mathrm{mM} N A D H$ ( $\mathrm{pH}$ 7,5 potasyum fosfat tamponu), $S O ̈ D(40 \mathrm{~W}, 20 \mathrm{kHz} S O ̈ D, 1 s$ uygulama $+1 \mathrm{~s}$ ara olacak şekilde $2 \mathrm{dk})$ ) (NADH oxidase activities)

\begin{tabular}{lc}
\hline Mikroorganizma & Aktivite (U/mL) \\
\hline L. kefir $\left(\mathrm{O}_{2}\right.$ 'siz ortamda üretilen) & 0,960 \\
R. glutunis & 0,014 \\
R. oryzae & - \\
R. arrhizus & - \\
\hline
\end{tabular}

Tablo 1'de görüldüğü üzere, $\mathrm{O}_{2}$ 'siz ortamda üretilen L. kefir'e $20 \mathrm{kHz}$ SÖD $80 \mathrm{~W}$ güçte $1 \mathrm{dk}$ sürekli uygulama $+1 \mathrm{dk}$ ara koşullarında $3 \mathrm{kez}$ uygulama yapıldığında NADH oksidaz aktivitesi $0,572 \mathrm{U} / \mathrm{mL}$ iken aynı cihazla $20 \mathrm{kHz}$ SÖD $40 \mathrm{~W}$ güçte, 1s uygulama+1s ara olacak şekilde 2 dk uygulandığında NADH oksidaz aktivitesi $0,96 \mathrm{U} / \mathrm{mL}$ (Tablo 3) olarak bulunmuştur. Hücre zarında bulunan NADH oksidaz enziminin serbest kalması için SÖD uygulaması olumlu etki göstermiştir. Fakat uzun süreli ve yüksek güçte uygulandığında enzim aktivitesi daha düşük bulunmuştur. Bunun nedeninin, uzun süreli ve yüksek güçte uygulama sırasında SÖD'nın enzim yapısına zarar vermiş olabileceği düşünülmüştür. Bu nedenle SÖD mikroorganizmaya yeterli enerji yoğunluğunda uygulanmalıdır.

\subsection{Rasemik Propranololün Yükseltgenmesi (Oxidation of Racemic Propranolol)}

Kullanılan mikroorganizmalar arasında ADH ve NADH oksidaz aktivitesi en yüksek olan mikroorganizma L. kefir NRRL B-1839 olarak belirlendiğinden bu mikroorganizma tüm hücre olarak kullanılarak tepkime gerçekleştirilmiştir. Rasemik propranololün yükseltgenme tepkimesi öncelikle $1 \mathrm{mM}$ substrat derişimi, $200 \mathrm{~g} / \mathrm{L}$ mikroorganizma (L. kefir) derişiminde Tris- $\mathrm{HCl}$ tamponunda $(50 \mathrm{mM}, \mathrm{pH}$ 7,5), $30^{\circ} \mathrm{C}$ ve $180 \mathrm{rpm}$ karıştırma hızındaki orbital çalkalayıcıda gerçekleştirilmiştir. Tepkime hacmi $10 \mathrm{~mL}$ 'dir fakat Şekil 2'de görüldügü gibi kofaktör rejenerasyonunun gerçekleşmesi için $\mathrm{O}_{2}$ gerektiğinden tepkime, 250 mL'lik tepkime kabında gerçekleştirilmiştir. 6 günlük tepkime süresinin sonunda enantiyomerik aşırılık (\% ee) \%1,5 bulunmuştur. Bir de, tepkime ortamına kofaktör rejenerasyonu için hücre içinde yeterli miktarda bulunmaması ihtimaline karşı tepkimenin başlangıcında 0,5 mM NADPH eklenerek aynı koşullarda tepkime gerçekleştirilmiştir. Fakat \% ee değeri değişmemiştir.

Geueke vd. (2003) çalışmasından Lactobacillus brevis mikroorganizmasının $\mathrm{O}_{2}{ }^{\prime}$ li ortamda üretildiğinde $\mathrm{NADH}$ oksidaz aktivitesinin, $\mathrm{O}_{2}$ 'siz ortamda üretildiğinde $\mathrm{ADH}$ aktivitesinin daha yüksek olduğu bilgisi edinilmişti [27]. Bu bilgi ışığında $\mathrm{O}_{2}{ }^{\prime}$ li ve $\mathrm{O}_{2}$ 'siz ortamda üretilen $L$. kefir mikroorganizmasından eşit miktarda hücre kullanılarak, daha düşük substrat derişimde ve farklı başlangıç hücre derişimlerinde tepkimeler gerçekleştirilmiş ve elde edilen sonuçlar Tablo 4'te verilmiştir. Hücre derişimi yüksek olduğunda kütle aktarım kısıtlamasına neden olabileceğinden 20-400 g/L derişim aralığında çalışılmıştır. Görüldügü gibi substrat derişiminin düşmesinin, $\mathrm{O}_{2}{ }^{\prime} l i$ ve $\mathrm{O}_{2}$ 'siz ortamda üretilen hücrelerin birlikte kullanılmasının ve farklı başlangıç hücre derişimlerinde çalışılmasının kayda değer bir etkisi olmamıştır ve en yüksek \% ee değeri \%3,61 olarak bulunmuştur. 
Tablo 4. Rasemik propranololün yükseltgenme koşulları $\left(C_{o}=0,1 \mathrm{mM}, \mathrm{V}=10 \mathrm{~mL}\right.$, Tris-HCl tamponu (50 $m M, p H$ 7,5), 5 gün, L. kefir) (Oxidation conditions of racemic propranolol)

\begin{tabular}{ccccc}
\hline $\begin{array}{c}\text { Mikroorganizma derişimi } \\
(\mathbf{g} / \mathbf{L})\end{array}$ & NAD ilavesi & \% ee & Konfigürasyon & \% C \\
\hline $20(10+10)^{*}$ & - & 3,07 & $\mathrm{~S}$ & 9,93 \\
$200(100+100)^{*}$ & - & 3,19 & $\mathrm{R}$ & 33,27 \\
$400(200+200)^{*}$ & - & 3,36 & $\mathrm{R}$ & 39,82 \\
$200(100+100)^{*}$ & $\sqrt{ }$ & 3,61 & $\mathrm{R}$ & 23,72
\end{tabular}

* $\mathrm{O}_{2}$ 'li ve $\mathrm{O}_{2}$ 'siz ortamda üretilen $L$. kefir mikroorganizmasından eşit miktarda hücre kullanılmış ve tepkime ortamındaki derişimleri parantez içinde belirtilmiştir.

\% ee değerinin 3,61 olarak bulunduğu tepkime sonucu ile aynı derişimdeki tepkime ortamının mikroorganizma eklenmeden gerçekleştirilen kontrol deneyinin HPLC analiz sonuçlarının karşılaştırılması Şekil 6'da verilmiştir. Buna göre L. kefir tepkimeyi katalizlemekte ve yaklaşık olarak 9. ve 11. dakikalarda çıkan propranolol enantiyomerlerinin pik alanları küçülmektedir. Ancak tepkimeyi stereoseçimli olarak katalizleyememektedir.

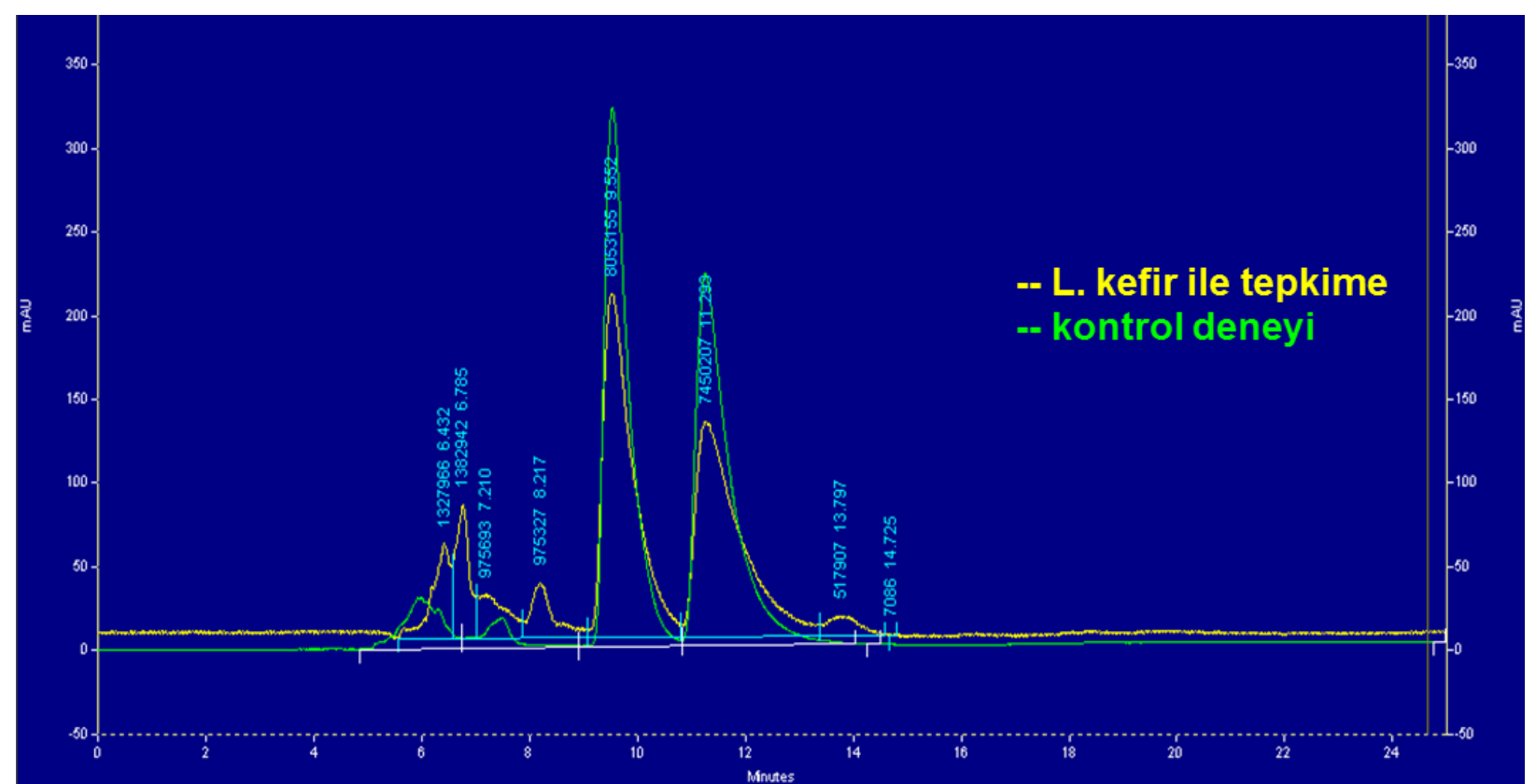

Şekil 6. L. kefir ile gerçekleştirilen tepkimenin HPLC analiz sonucunun kontrol deneyi ile karşllaştırlması (The comparing of HPLC analysis result of oxidation reaction with L. kefir and control experiment)

Sonuç olarak, enzim aktivite ölçümleri sonucunda kullanılan mikroorganizmalar arasında ADH ve NADH oksidaz aktivitesi en yüksek olan L. kefir mikroorganizması olarak bulunmuştur. Bu mikroorganizma propranololün yükseltgenmesi tepkimesinde kullanıldığında ise Şekil 6'da görüldüğü üzere tepkimeyi katalizlediği, belli bir dönüşümün olduğu fakat seçimli davranamadığı gözlenmiştir. Çalışma kapsamında propranololün enantiyomerik saflıkta üretimi amaçlandığından, ADH ve NADH oksidaz enzimlerini içeren ve propranololün yükseltgenmesini seçimli olarak katalizleyecek uygun mikroorganizmayı belirlemek için çalışmalar devam etmektedir. 


\section{SONUÇLAR (CONCLUSIONS)}

Farmasötik açıdan önem taşıyan $\beta$-blokerlardan biri olan propranololün enantiyomerik saflıkta üretimi kapsamında rasemik propranololün yükseltgenme tepkimesinde kullanılacak olan uygun mikroorganizma araştırılmıştır. Bu tepkimenin gerçekleşmesi için ADH ve NADH oksidaz enzimi gerekli olduğundan farklı mikroorganizmalarda bu enzimlerin aktiviteleri ölçülmüş ve kullanılan mikroorganizmalar arasında en yüksek aktivitelerin $L$. kefir'de olduğu belirlenmiştir. L. kefir mikroorganizması rasemik propranololün yükseltgenmesi tepkimesinde kullanıldığında ise \% ee değeri en yüksek \%3,61 olarak bulunmuştur. Bu da L. kefir' in tepkimede seçimli davranamadığını göstermektedir. Sonuç olarak, L. kefir' in ADH ve NADH oksidaz enzimlerini içerdiği, HPLC pikleri incelendiğinde tepkimeyi katalizlediği fakat tepkimede stereoseçimli davranamadığı anlaşılmıştır.

Aktivite deneyleri sonucunda hücre içi ve hücre zarında olduğu bilinen ADH ve NADH oksidaz enzimlerinin hücre dışına çıkarılması için SÖD (ya da enzimin çıkması için başka hücre parçalama yöntemlerinin) uygulanmasının gerekli olduğu anlaşılmıştır. L. kefir' 'in NADH oksidaz aktivitesinin SÖD uygulandığında yaklaşı 100 kat artması bu gerekliliği ortaya koymaktadır.

Derasemizasyon yöntemiyle ilişkili olarak ise uygun mikroorganizma seçimi üzerinde çalışmalar devam etmektedir. Rasemik propranololün yükseltgenmesi tepkimesini seçimli olarak katalizleyebilen bir mikroorganizma bulunduğu durumda tepkimenin optimum koşullarının belirlenmesi hedeflenmektedir.

\section{SEMBOLLER (SYMBOLS)}

ADH: Alkol dehidrojenaz

$\mathrm{C}_{\mathrm{R}}:(\mathrm{R})$-propranololün derişimi

Cs : (S)-propranololün derişimi

$\mathrm{C}_{\mathrm{o}}$ : Rasemik propranololün başlangıç derişimi

$\mathrm{C}_{\text {So }}$ : (S)-propranololün başlangıç derişimi

NAD: Nikotinamid adenin dinükleotid

PDA: Patates dekstroz agar

PDB: Patates dekstroz besiyeri

SÖD : Ses ötesi dalga

UYM: Genel maya üreme ortamı

$\mathrm{V}:$ Tepkime hacmi

\% C : Dönüşüm

$\%$ ee : Enantiyomerik aşırılık

\section{TEŞEKKÜR (ACKNOWLEDGMENT)}

Bu çalışma Ankara Üniversitesi Bilimsel Araştırma Projeleri Koordinatörlüğü tarafından 14L0443004 nolu proje ile desteklenmiştir.

\section{KAYNAKLAR (REFERENCES)}

[1] J. Agustian, A. H. Kamaruddin, S. Bhatia, Single enantiomeric $\beta$-blockers-The existing technologies. Process Biochem., 45 (2010) 1587-1604.

[2] I. T. Lund, P. L. Bockmann, E. E. Jacobsen, Highly enantioselective CALB-catalyzed kinetic resolution of building blocks for $\beta$-blocker atenolol. Tetrahedron, 72 (2016) 7288-7292. 
[3] R. Mehvar, D. R. Brocks, Stereospecific Pharmacokinetics and Pharmacodynamics: Cardiovascular Drugs (Chapter 7), Chirality in Drug Design and Development, Editors; I. K. Reddy, R. Mehvar, Marcel Dekker, New York, 2004.

[4] D. Zelaszczyk, K. K. Kononowicz, Biocatalytic approaches to optically active $\beta$-blockers. Curr. Med. Chem., 14 (2007) 53-65.

[5] A. Kamal, G. B. R. Khanna, T. Krishnaji, V. Tekumalla, R. Ramu, New chemoenzymatic pathway for $\beta$-adrenergic blocking agents. Tetrahedron: Asymmetry, 16 (2005) 1485-1494.

[6] M. I. R. M. Santoro, H.S. Cho, E. R. M. Kedor-Hackmann, Enantiometric separation and quantitative determination of propranolol in tablets by chiral high-performance liquid chromatography. Drug Dev. Ind. Pharm., $27: 7$ (2001) 693-697.

[7] A. Kamal, M. Sandbhor, A. A. Shaik, Chemoenzymatic synthesis of (S) and (R)-propranolol and sotalol employing one-pot lipase resolution protocol. Bioorganig \& Medicinal Chemistry Letters, 14 (2004) 4581-4583.

[8] A. M. Escorcia, D. Molina, M. C. Daza, M. Doerr, Acetylation of (R,S)-propranolol catalyzed by Candida antarctica lipase B: An experimental and computational study. J. Mol. Catal. B: Enzym., 98 (2013) 21-29.

[9] K. Stoschitzky, W. Lindner, G. Zernig, Racemic beta-blockers-fixed combinations of different drugs. Journal of Clinical and Basic Cardiology, 1: 1 (1998) 15-19.

[10] X. D. Kong, H. L. Yu, S. Yang, J. Zhou, B. B. Zeng, J. H. Xu, Chemoenzymatic synthesis of (R)and (S)-propranolol using anengineered epoxide hydrolase with a high turnover number. J. Mol. Catal. B: Enzym., 122 (2015) 275-281.

[11] B. Li, Y. Nie, X. Q. Mu, Y. Xu, De novo construction of multi-enzyme system for one-pot deracemization of (R,S)-1-phenyl-1,2-ethanediol by stereoinversion of (S)-enantiomer to the corresponding counterpart. J. Mol. Catal. B: Enzym., 129 (2016) 21-28.

[12] D. S. Solano, P. Hoyos, M. J. Hernaiz, A. R. Alcantara, J. M. Sanchez-Montero, Industrial biotransformations in the synthesis of building blocks leading to enantiopure drugs. Bioresour. Technol., 115 (2012) 196-207.

[13] M. Sudar, Z. Findrik, M. V. Domanovac, D. V. Racki, Coenzyme regeneration catalyzed by NADH oxidase from Lactococcus lactis. Biochem. Eng. J., 88 (2014) 12-18.

[14] S. V. Damle, P. N. Patil, M. M. Salunkhe, Biotransformations with Rhizopus arrhizus and Geotrichum candidum for the preparation of (S)-Atenolol and (S)-Propranolol. Bioorganic\&Medicinal Chemistry, 8 (2000) 2067-2070.

[15] M. Colnik, M. Primozic, M. Habulin, Use of supercritical carbon dioxide for proteins and alcohol dehydrogenase release from yeast Saccharomyces cerevisiae. J. Supercrit. Fluids, 65 (2012) 11-17.

[16] K. S. Ojha, T. J. Mason, C. P. O’Donnell, J. P. Kerry, B. K. Tiwari, Ultrasound technology for food fermentation applications. Ultrason. Sonochem., 34 (2017) 410-417.

[17] J. Geciova, D. Bury, P. Jelen, Methods for disruption of microbial cells for potential use in the dairy industry - a review. Int. Dairy J., 12 (2002) 541-553.

[18] A. Telefoncu, F. Zihnioğlu, J. Salnıkow, A. Kılınç, Biyokimyada Temel ve Modern Teknikler, Biyokimya Lisansüstü Yaz Okulu, İzmir, 2000.

[19] P. R. Gogate, A. B. Pandit, Application of cavitational reactors for cell disruption for recovery of intracellular enzymes. J. Chem. Technol. Biotechnol., 83 (2008) 1083-1093. 
[20] B. Özbek, K.Ö. Ülgen, The stability of enzymes after sonication. Process Biochem., 35 (2000) 10371043.

[21] A. Lateef, J. K. Oloke, S. G. Prapulla, The effect of ultrasonication on the release of fructosyltransferase from Aureobasidium pullulans CFR 77. Enzyme Microb. Technol., 40 (2007) 1067-1070.

[22] G. Cea, L. Wilson, J. M. Bolivar, A. Markovits, A. Illanes, Effect of chain length on the activity of free and immobilized alcohol dehydrogenase towards aliphatic alcohols. Enzyme Microb. Technol., 44 (2009) 135-138.

[23] W. Hummel, B. Riebel, Isolation and biochemical characterization of a new NADH oxidase from Lactobacillus brevis. Biotechnol. Lett, 25 (2003) 51-54.

[24] Y. L. Li, J. H. Xu, Y. Xu, Deracemization of aryl secondary alcohols via enantioselective oxidation and stereoselective reduction with tandem whole-cell biocatalysts. J. Mol. Catal. B: Enzym., 64 (2010) 48-52.

[25] H. Ç. Kazıcı, Ü. Mehmetoğlu, Use of the plant as biocatalysts for producing enantiomerically pure seconder alcohol. Journal of the Faculty of Engineering and Architecture of Gazi University, 30: 1 (2015) 49-56.

[26] D. M.-R. D. Temino, W. Hartmeier, M. B. Ansorge-Schumacher, Entrapment of the alcohol dehydrogenase from Lactobacillus kefir in polyvinyl alcohol for the synthesis of chiral hydrophobic alcohols in organic solvents. Enzyme Microb. Technol., 36 (2005) 3-9.

[27] B. Geueke, B. Riebel, W. Hummel, NADH oxidase from Lactobacillus brevis: a new catalyst for the regeneration of NAD. Enzyme Microb. Technol., 32 (2003) 205-211. 